\title{
Design For Service Innovation
}

\author{
Harry Katzan, Jr., Webster University, USA
}

\begin{abstract}
This paper covers service innovation for service scientists. The subject has not been accorded the attention it deserves, because of inadequate professional and academic attention to services, in general, and service design, in particular. The changing of one's perception of the human landscape from products to services is indeed cumbersome and entails a lot of effort on the part of the service establishment and the service entrepreneur. However, a new view of an age-old agenda in light of the ongoing move to globalization can be enlightening and rewarding. If Thomas Edison were engaged in services, he would have put it this way, "Service innovation is 90\% perspiration and 10\% inspiration." Heretofore, innovation has been unfortunately aligned with the business community that has been distracted by an outdated and simplistic view of competitive advantage based on comparative economics. Effective service innovation is based on differential economics through service delivery that supplies better services as seen by the customer. Service innovation applies equally well, if not more so, to the other human endeavors of engineering, government, education, social services, political science, and a wide-range of unclassified interpersonal relations. The paper gives a modern view of service, innovation, service innovation, and how to unearth services innovation in a practical sense. Also, the point is made herein that service innovation is basic to the constituency of the human condition.
\end{abstract}

Keywords: Service; Service Thinking; Service Design; Innovation; Service Innovation

\section{SERVICE}

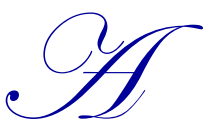

service is an interaction between two entities that co-create value, as long as the constituent roles are complementary. ${ }^{1}$ The receiver of the service may be a distinct service object. A service is a process resulting in tangible value when the associated sequence of steps is instantiated (Katzan, $2008)^{2}$. The term "service" is an overloaded word. The constituent steps of a service process may be service components arranged in a hierarchical or possible a recursive fashion. All products are essentially services - a statement that must dismay economists and accountants - and some products and services may have an intangible value that exceeds their tangible value. For example, if a person drives a Porsche Panamera to his or her place of business, there is considerably more to the automobile product than the element of transportation. Once we recognize intangible service, it opens the door for an enhanced role for service in the domain of everyday life.

One's persona is a service signaling education, position, and leisure or social status. Form of dress, table manners, quality of speech, and even patterns of activity can also be construed as services. In fact, one's occupation can be viewed as a service indicating the social position of an individual. Are all actions and conditions a form of service? Probably.

Clearly, the scope of service innovation is enormous, and this paper applies functional analysis to uncover a wide range of applicable phenomena. In many instances, it is not entirely clear exactly who the provider is and precisely clear who is the client. A prototypical example is the common photo of an experienced physician, a trainee doctor, and a patient with the caption, "who's the client and who's the service provider?"

\footnotetext{
${ }^{1}$ This means that one role is the service provider and the other role is the service client.

${ }^{2}$ Katzan, H. 2008. Service Science: Concepts, Technology, Management. New York: iUniverse, Inc.
} 


\section{INNOVATION}

Innovation generally refers to the creation of new or improved products, services, or technologies that are recognized by individuals, groups, organizations, governments, or society in general. Innovation usually reflects positive change, by making products or services more efficient, effective, more useful, and more usable. The operant question is, "for whom?" The provisioning of multichannel access to government services, in some jurisdictions, for example, is usually regarded as an instance of innovation. The client, on the other hand, has to make an "up front" commitment to that form of activity, so who really benefits? The client has to go out of his or her way to benefit from the innovation, while the government employee is free to engage in other activity, not necessarily productive in nature. Another familiar example is the ending of a news segment by referring the viewer to the station's web site with the familiar phrase, "You can find more about this story on our web site at www.xyz.com." This is clearly innovation, but its value proposition for the client is questionable.

There is an ethical component to innovation. Is the innovation of online shopping to entice people into purchasing something they didn't need in the first place ethical? This is an interesting question when considering society's inability to resist temptation.

Innovation is synonymous with change, for which there is always a reason. However, an operational adjustment resulting from a societal, organizational or governmental change is not innovation. Innovation is a change in a service - yes, all products are services - that results in a positive change to the value proposition for the provider and for the client (Vargo \& Akaka, 2009).

Most product and service innovation - to revert to the older conception of products and services for a moment - is effectively hidden to the general public and to the consumer and occurs at the science and technology level to increase reliability and functionality. Engineering and design usually supply the following:

- $\quad$ Products that are more reliable to reduce warranty costs

- $\quad$ Products that perform better

- $\quad$ Products that provide functionality not previously available

- $\quad$ Products that look better

On the other hand, there is another side to the coin. At the service level, we are looking for services that supply the following:

- $\quad$ Services that are more useful

- $\quad$ Services that are more usable

- $\quad$ Services that provide a better user experience

The latter category concerns elements that are human centered and give rise to discipline sometimes known as "service innovation." If there were an innovation cycle, it would cycle through the following activities:

- $\quad$ Improve the process

- Improve the result/experience

- Improve the economics (value proposition for provider and client)

- Improve the number of customers

- $\quad$ Return to the first entry

The sources of innovation are generally regarded as manufacturing innovation and end-user innovation. It is customarily achieved by formal research and development or by on-the-job modification of design, commonly regarded as "learning by doing." There is a bias toward the former and many forms of diffusion have been developed to support that bias (Rogers, 1962) ${ }^{4}$.

\footnotetext{
${ }^{3}$ Vargo, S. \& Akaka, M. 2009. Service-Dominant Logic as a Foundation for Service Science. Service Science, 1(1): 32-41.

${ }^{4}$ Rogers, E. 1962. Diffusion of Innovation, New York: The Free Press.
} 
The economist Joseph Schumpeter $(2008)^{5}$ associated innovation with "creative destruction," whereby previously created productive forces are periodically destroyed to make room for new ideas, resulting in instability of the business cycle. Layoffs of workers with obsolete skills and downsizing to free-up capital for creation are normally associated with intense periods of innovation.

\section{DESIGN THINKING}

Design thinking involves people and culture. When a service design involves a person-to-person interaction, for example, the efficacy of that interaction involves more than the exchange of acts or symbols. The point-of-view of the participants is basic to how the service interaction is perceived as an important component of the total service experience. The client or customer's expectations will determine if a highly predictable or a highly variable interaction should take place. Design thinking is a discipline that combines the designer's knowledge, sensitivity, and design perspective with technical feasibility and design methods to assist a client in resolving a perceived need so as to provide value for the client and the designer (Brown, 2008) ${ }^{6}$.

Creation of a well-thought out customer experience through a combination of approaches, related by a common denominator of a perceived problem statement, including holistic design, cross-disciplinary synthesis, a useful and usable delivery system, and an effective and efficient service process, is the result of five fundamental principles of good service design (Stickdorn \& Schneider, 2010) ${ }^{7}$.

- $\quad$ User-centered - The objective of service, by definition, is to satisfy customer needs.

- Co-creative - The focus of service design involves the considerations of the stakeholders who should cooperate in the process of service design. (There are two processes: the design process and the service process.)

- $\quad$ Sequencing - Any service design, other than trivial service endeavors, should have a timeline reflecting the service design process, and the state of the participants at that point in time.

- $\quad$ Evidencing - A well-designed service should have a foot-print of front stage and back stage processes (covered later). The value of both tangible and intangible services should be clearly evidenced, as part of the service design experience.

- Holistic - Service, of any type, resides in a culture. In many instances, the service designer collaborates with the client in its culture to establish service for customers, who may have a unique a culture. Thus, a good service designer should be culturally ambidextrous.

In the application of the five principles, it is important to focus on four stakeholders from the service environment. They are the client/customer, the service provider, the principal, and the designer, supporting the contention that service design is not a job description but a process.

\section{DESIGN METHODS}

Since service design is a creative process, one would naturally expect a wide variety of approaches to the subject. Six "tools" of service design are presented here, and from then on, the designer is on his or her own to develop an individual approach. When collaborating with a client in this regard, there seems to be no "right or wrong." We are going to cover the following six subjects: service view, narrative, process diagram, service blueprinting, touchpoints, and interaction design.

The service view represents the problem statement. Initially, the designer is faced with the possibility that the client does not really know what it wants and has not thought the situation through. Several techniques can be employed for needs research: brainstorming, crowdsourcing, customer shadowing, contextual interviews, fictitious customer profiles - known as personas, and customer sequencing through a nominal service process.

\footnotetext{
${ }^{5}$ Shumpeter, J. 2008. Capitalism, Socialism, and Democracy (3e). New York: Harper Perrennial.

${ }^{6}$ Brown, T. 2008. Design Thinking. Harvard Business Review, (June 2008), p. 1-10.

${ }^{7}$ Stickdorn, M. \& Schneider, J. 2010. This is Design Thinking. Amsterdam: BIS Publishers.
} 
A narrative is a verbal or written description of a hypothetical run-through of a service process from which the designer and client can establish component services, touchpoints, events wherein the client server and customer interact, and operational conditions that should be met, known as evidence items. The idea behind evidence is to inform the customer what is being done and how well things are going.

Process design model reflects the interaction between service entities. Unlike product design, the components of a service are a combination of integrated processes, people, skills, and materials that must be planned in advance (Goldstein, Johnston, Duffy, \& Rao, 2002) ${ }^{8}$. One means of describing a service process is through the use of a "bubble" diagram, often used in investigation to unravel a complex sequence of events. The degree of interaction between service components is clearly evident from a process diagram but the precise nature of each interaction is not specified.

A service blueprint is a flow chart used to describe the design of a service process. It is a tool for delineating the steps through which the designer or customer will go to establish the design objective.

There are several uses of the design blueprint, the most common of which is to identify the constituent service events that are visible to the customer, such as the process flow, the provider interactions, and service bottlenecks. In so doing, five parts of a service process are identified: physical evidence, customer actions, frontstage service provider actions, back-stage provider actions, and support processes (Bitner, Ostrom, \& Morgan 2007'; Shostack, $1984^{10}$; Zeithaml \& Bitner, 2000 ${ }^{11}$; Norman, 2011 ${ }^{12}$ ). In designing, there are usually three main things the designer has to think about: what the customer does and experiences, what the service provider does in conjunction with the customer to gather information and execute service events, and what goes on behind the scenes to support the service provider. It is important to recognize that the customer and the service provider both go through a series of steps and the blueprint shows where they interact.

The category of physical evidence is a catch all for the supplementary activities usually performed by the customer; they are necessary for getting a service going and sustaining the service. This is the acquisition phase and part of the invocation phase. Prototypical examples are making a reservation or appointment, driving to the service facility, finding a parking spot, and so forth.

The category of customer actions refers to what the customer does upon entering the service factory, shop, or information portal, and the activities performed during the service process, as well. They might include finding a table and reading the menu in a restaurant, for example, or checking in and going to one's room during a hotel stay or buying a ticket and going to one's seat in a form of public transportation.

The front stage refers to the actions performed by the service provider that are seen by the customer, either physically or logically, such as taking an order, selling a ticket, or ignoring a customer. The customer actions and the front-stage service provider actions are like two sequences, running in parallel, with a hypothetical dividing line between them known as the line of interaction.

The category of back stage provider actions denotes service activities performed by the service facility on behalf of a customer but not ordinarily seen by the customer. During a hotel check-in, it is the computer operations behind the counter that supply assistance to the employee in assigning a room and providing supplementary services that are expected but not requested by the hotel guest. In a restaurant, it is food preparation by the kitchen staff. The separation between the front stage and the back stage is known as the line of visibility. More specifically, of course, it is the separation between the front-stage provider actions and the back-stage provider actions.

\footnotetext{
${ }^{8}$ Goldstein, S., Johnston, R., Duffy, J., \& Rao, J. 2002. The service concept: the missing link in service design research? Journal of Operations Management 20:121-13.

${ }^{9}$ Bitner, M., Ostrom, A., \& Morgan, F. 2007. Service Blueprinting: A Practical Technique for Service Innovation. Center for Service Leadership, Arizona State University.

${ }^{10}$ Shostack, G. 1984. Designing Services that Deliver. Harvard Business Review, 62(1): 133-139.

${ }^{11}$ Zeithaml, V. \& Bitner, M. 2000. Services Marketing: Integrating Customer Focus Across the Firm (2e). New York: Irwin McGraw Hill.

${ }^{12}$ Norman, D. 2011. Living with Complexity. Cambridge, MA: The MIT Press.
} 
Practically, all forms of service require support activities, such as the reservations computer in the hotel business and the infrastructure, operational and supplier functions in a restaurant. This form of service is known as support processes that are separated from the back-stage functions by a line of internal interaction.

Interaction design involves the dialog between a person and a production or service, based on a series of touchpoints supporting the instantiation of a service (Stickdorn et al., 2010 13 Kolko, 2011 14 ). The idea behind interaction design is to assist in making useful products and services usable (Norman, 2011) ${ }^{15}$. Utility (i.e., the notion of usefulness) is concerned with functional benefits of a service object, while usability involves an assessment of how well the interaction components are sequenced and how adjacent elements are interrelated. Interaction design shapes the behavior of the user of a product or service (Kolko, 2011) ${ }^{16}$. The design of a series of interactions effectively creates a user experience that determines whether the experience is successful or not. "The user experience is the totality of end users' perception as they interact with a product or service" (Kuniavsky, 2010, p. $14^{17}$ ). The perceptions include effectiveness, efficiency, and affective satisfaction. Collectively, the three aspects of perception contribute to the nebulous concept of service quality. An interaction is a bridge between the front stage and the back stage that normally assumes either of the following forms: person-to-person services, technologyenhanced person-to-person services, self-service, and multichannel services (Glushko \& Tabas, 2010) ${ }^{18}$. Person-toperson service refers to a face-to-face encounter that provides tangible evidence that a service is being delivered (Glushko, 2010) ${ }^{19}$. Technology-enhanced person-to-person service refers to the case wherein the provider or the customer uses technology in creating an information-intensive service encounter. Self-service uses technology for enhancing the service provider's viewpoint in supplying service - as in self-service hotel or baggage check-in or online purchasing. Multichannel service refers to the case where a service provider supplies online and in-store services, as in well-known instances of book and apparel marketing.

\section{SERVICE INNOVATION}

Service innovation is the introduction of new or significantly improved services (OECD, 2006) ${ }^{20}$. Innovative services can be stepwise improvements, termed incremental innovation, or be radical innovations that are disruptive to the market or industry. In the former case, the innovation may be incremental but new to the firm (Mohapatra, Cheney, Shapira, Youtie, Lamos, \& Bhaskarabhatia, 2006) ${ }^{21}$. Innovation incorporates inventions and insight that generates economic and social value (NII, 2004 ${ }^{22}$ ). In general, the source of innovation can be internal to a firm or result from a variety of external sources, termed open innovation (Chesbrough, 2003) ${ }^{23}$. In general, service innovation benefits both the provider and the client.

Through service innovation, something changes in the service domain, and a useful model of those changes is reflected in the den Hertog $(2000)^{24}$ model that includes four dimensions of service innovation: the service concept, the client interface, the service delivery system, and the technology options.

The service concept includes the manner in which the service is delivered, the customer's service experience, the service result, and the value of the service to both the provider and the customer. The client interface is descriptive of the roles played by the provider and the client, and is a prime determinant of the client experience. The service delivery system describes the packaging, delivery, and the mode of delivery, whether it be

\footnotetext{
${ }^{13}$ Stickdorn, M. \& Schneider, J. 2010. This is Design Thinking. Amsterdam: BIS Publishers.

${ }^{14}$ Kolko, J. 2011. Thoughts on Interaction Design. New York: Elsevier.

${ }^{15}$ Norman, D. 2011. Living with Complexity. Cambridge, MA: The MIT Press.

${ }^{16}$ Kolko, J. 2011. Thoughts on Interaction Design. New York: Elsevier.

${ }^{17}$ Kuniavsky, M. 2010. Smart Things: Ubiquitous Computing User Experience Design. New York: Elsevier/Morgan Kaufmann.

${ }^{18}$ Glushko, R. \& Tabas, L. 2010. Designing Services by Bridging the "Front Stage" and "Back Stage." (ischool.berkekey.edu/glushko)

${ }^{19}$ Glushko, R. 2010. Seven Contexts for Service System Design. (ischool.berkekey.edu/glushko)

20 OECD. 2006. Innovation and Knowledge-intensive Service Activities, (https://www.oecd.org/document/56/0,3343, en 2649_34273_362743360_1_1_1_1,00.html).

${ }^{21}$ Mohapatra, S., Cheney, D., Shapira, P., Youtie, J., Lamos, E., \& Bhaskarabhatia, A. 2006. Product and Service Innovation, NIST, SRI International, and Georgia Tech Program in Science, Technology, and Innovation Policy.

${ }^{22}$ NII. 2004. Innovate America, Council on Competitiveness, Washington, DC.

${ }^{23}$ Chesbrough, H. 2003. Open Innovation. Cambridge, MA: Harvard Business School Press.

${ }^{24}$ den Hertog, P. 2000. Knowledge-intensive business services as co-producers of innovation. International Journal of Management, (http://www.centrim.bus.bton.ac.uk/research/Rise/theme_denhertog.pdf).
} 
person-to-person or technology enhanced. Technology options suggest the use of computer and information technology to support and encapsulate the support the delivery of services. Clearly, the den Hertog model is a general framework that suggests the myriad of points in the service design cycle that are sources of service innovation. In actual practice, most service innovations will incorporate a combination of the four dimensions $\left(\right.$ Wiki, 2010) ${ }^{25}$.

Miles $(1993)^{26}$ covers a set of four service attributes, each of which is associated with a certain type of innovation, normally resulting from a problem in service design, service delivery, or client experience. The general categories are: (1) Features of services associated with service production; (2) Features of services associated with service product; (3) Features of services associated with services consumption; and (4) Features of services associated with services markets. We are going to concentrate on features (2) and (3) under the title of "experiential services."

\section{EXPERIENTIAL SERVICES}

Clearly, service innovation is achieved through service design and is the reason that service design was summarized in an earlier section. Each touchpoint presents an opportunity for service innovation. With experiential services, the customer experience can be viewed as a "customer journey," built up over a period of time. As such the journey will consist of multiple touchpoint and multiple components. This approach will emphasize the role of the customer in service design (Voss, Tsikriktsis, \& Frohlich, 2002) ${ }^{27}$.

"Experiential services are services where the focus is on the experience of the customer when interacting with the organization, rather than just the functional benefits following from products and services delivered" (Voss $\&$ Zomerdijk, 2007) ${ }^{28}$. We are going to use the Walt Disney World experience cycle of Departure, Savoring, Anticipating, Arrival, and Experience as a conceptual model for this presentation. The corresponding areas for innovation are the physical environment, service employees, service delivery process, fellow customers, and back office support.

The physical environment is the setting in which the service is delivered and is concerned with navigation within a service facility (Bitner, 1992) ${ }^{29}$. The category of service employees refers to customer engagement and includes the behavior of employees as well as auxiliary services. The service delivery process refers to the actions required to present the expected service. The behavior of fellow customers is instrumental in experiential design and can result from crowed facilities and unruly people. On the other hand, socializing can make a service experience more enjoyable, so that the subject of fellow customers is a particularly sensitive item in service innovation. Lastly, back office support indirectly supports the customer experience, even though the back office may not directly interact with customers. Back office training is important is this regard.

\section{SUMMARY}

Service innovation is a general subject related to either or all of three areas of study: the service product, the service process, and the service organization. Service innovation is designed into the total service offering through the traditional design methodology, as along as it results from design thinking.

\section{AUTHOR INFORMATION}

Professor Harry Katzan, Jr. is the author of books and papers on computer science, decision science, and service science. He teaches information security, terrorism, and rick management in the MBA program at Webster University.

\footnotetext{
${ }^{25}$ Wiki. 2010. Service Innovation. (hip://en.wikipodia.org/wiki/Service_innovation.

${ }^{26}$ Miles, I. 1993. Services in the New Industrial Economy. Futures, 25(6):653-672.

${ }^{27}$ Voss, C., Tsikriktsis, N., and Frohlich, M. 2002, Case research in operations management. International Journal of Operations \& Production Management, 22(2): 195-219.

${ }^{28}$ Voss, C. \& Zomerdijk, L. 2007. Innovation in Experiential Services - An Empirical View. Published in Innovation in Services, DTI Occasional Paper No. 9, (http://www.dti.gov.uk/innovation/technology).

${ }^{29}$ Bitner, M. 1992. Servicescapes: The Impact of Physical Surroundings on Customers and Employees. Journal of Marketing, 56(2):57-71.
} 